\title{
Tecnologias digitais de rede e formação de educadores: a percepção dos estudantes sobre seu processo formativo
}

\section{Digital network technologies and teacher training: the students' perception of their formative process}

\author{
Lidiane Goedert, Karina Marcon \\ Universidade do Estado de Santa Catarina - Brasil
}

\begin{abstract}
Resumo
O objetivo deste estudo é analisar a percepção dos estudantes sobre o seu processo de apropriação de tecnologias digitais de rede no desenvolvimento da disciplina Didática da Educação a Distância, do Curso de Pedagogia a Distância da Universidade do Estado de Santa Catarina. Os dados foram coletados a partir de questionário online aplicado a oito turmas durante 2017/01. Os resultados evidenciaram que: a maioria dos estudantes reconhece a importância da apropriação de tecnologias digitais para sua atuação na educação básica; mais de $90 \%$ dos estudantes distinguem que as atividades propostas contribuíram para ampliar o conhecimento pedagógico das tecnologias; a dificuldade central associada pelos estudantes quanto à apropriação das tecnologias foi o idioma em inglês de alguns recursos.

Palavras-chave: tecnologias digitais de rede, formação de professores, educação a distância.
\end{abstract}

\begin{abstract}
The objective of this study is to evaluate students' perception about their knowledge appropriation of network digital technologies within the discipline of distance learning didactic. This is part of the Remote Pedagogy course at State University of Santa Catarina, Brazil. Data were collected through online questionnaires applied to eight course sections in 2017/01. Results indicated that the majority of students recognized the importance of knowledge appropriation of digital technologies for their future performance in school education. Additionally, more than $90 \%$ of students conceded that proposed activities contributed to increased pedagogical knowledge of technologies; and, the main difficulty to the knowledge appropriation process was the language, given that some resources are only available in English.

Keywords: Digital network technologies, teacher training, distance learning.
\end{abstract}

Vivemos um período marcado pela utilização generalizada das Tecnologias Digitais de Rede (TDR), especialmente a internet. Nesse cenário, as relações sociais têm sido fortemente influenciadas e transformadas, com repercussões econômicas, sociais, culturais, políticas e, consequentemente, educacionais.
Logo, essas alterações provocadas pela presença e uso massivo das TDR no cotidiano das pessoas também se revelam no contexto escolar através da informação e do conhecimento do mundo que as crianças adquirem desde pequenas por meio do contato com as variadas mídias (Riedner; Pischetola, 2016).

Sobre esse aspecto, Coutinho (2009) afirma que essas tecnologias geram múltiplas potencialidades, instituem inúmeros novos cenários e promovem ambientes (reais ou virtuais) extremamente ricos e promotores de uma multiplicidade de experiências pedagógicas, impulsionando as pessoas a conviverem com a ideia de que a aprendizagem é um processo que se desenvolve ao longo da vida, sem fronteiras de tempo e espaço. Esses fatores provocam novas percepções sobre aprender e ensinar, exigindo o repensar do papel da escola tanto em termos de organização estrutural quanto em relação ao currículo. Para a referida autora, a introdução das TDR no processo de ensino-aprendizagem provoca transformações que acontecem ao mesmo tempo que se questiona qual a função da escola e do professor neste novo contexto social.

Moreira, Monteiro e Barros (2015), salientam que na web 2.0, a aprendizagem em rede e as potencialidades deste "software social" trouxeram novos e instigantes desafios para os sistemas educativos. Dentre esses desafíos, os autores destacam como o principal deles a necessidade de conceber uma "nova" didática para a docência na web social, que se fundamente não somente no conhecimento científico, curricular e pedagógico, mas também num conhecimento tecnológico que possibilite planejar, conceber e utilizar as tecnologias nos processos ensino-aprendizagem. $\mathrm{O}$ atendimento desse desafio implica uma mudança de modelos pedagógicas centrados no professor para modelos mais participativos, colaborativos e sociais focados nos diferentes atores educativos.

A diversidade de ferramentas e potencialidades da web 2.0 é expressiva. No entanto, a sua inserção no ensino requer conhecimento tecnológicos das mesmas por parte dos professores, além do reconhecimento de suas 
possibilidades pedagógicas. A esse respeito, Moreira, Monteiro e Barros (2015) afirmam que, para que o professor possa dar uma resposta efetiva aos desafios que a introdução das ferramentas da web 2.0 no ensino suscita, é necessário que os seus conhecimentos e as suas competências na área das tecnologias sejam intensificados.

Nesse sentido, e considerando o cenário apresentado, entendemos que a formação inicial de educadores não pode mais acontecer dissociada de processos de apropriação tecnológica, contribuindo para sua inserção, especialmente, na educação básica, visando potencializar relações didáticas e contribuir para a inclusão digital de estudantes e professores. Em um curso a distância essa apropriação se potencializa em função dos processos de ensino-aprendizagem acontecerem mediados pelas tecnologias digitais.

Assim, tendo como base a ideia de que cursos de formação de professores a distância podem oportunizar processos de inclusão digital (Marcon, 2015), um dos propósitos da disciplina Didática da Educação a Distância (DEAD), oferecida na $4^{\mathrm{a}}$ fase do Curso de Pedagogia a Distância da UDESC, foi oportunizar aos estudantes o reconhecimento do ambiente virtual de aprendizagem como um espaço de interatividade e de apropriação de tecnologias. Nesse sentido, as atividades de aprendizagem propostas envolveram o conhecimento e utilização de diferentes recursos da web 2.0, tais como o Voki, Fábrica de Tirinhas, Toondoo, Prezi e StoryJumper, assim como a reflexão sobre o potencial pedagógico que possibilitam. Após o desenvolvimento da disciplina, com o objetivo de realizar uma avaliação da metodologia adotada e das tecnologias escolhidas, disponibilizamos um questionário para as turmas da $4^{\circ}$ fase, cujas questões objetivavam a análise da percepção dos estudantes sobre o seu processo de apropriação de tecnologias sob duas perspectivas: a pedagógica e a tecnológica. Os resultados desta pesquisa são socializados a seguir.

\section{Método}

Para analisar a percepção dos estudantes sobre o seu processo de apropriação de tecnologias digitais de rede no desenvolvimento da disciplina DEAD, realizamos uma investigação de caráter quantitativo e qualitativo, por meio de um questionário online. O questionário online foi disponibilizado no ambiente virtual da disciplina e aplicado a oito turmas da $4^{\mathrm{a}}$ fase do curso de Pedagogia a Distância da Universidade do Estado de Santa Catarina, durante o primeiro semestre de 2017. Para a análise dos saberes compartilhados efetivamos um estudo à luz de referenciais teóricos e publicações científicas que envolvem inclusão digital, tecnologias digitais de rede, processos educativos escolares e formação de educadores.

\section{Participantes}

Os sujeitos participantes da pesquisa compreendem 213 estudantes matriculados em oito turmas do curso de Pedagogia, no quarto semestre na disciplina DEAD. Entretanto, participaram efetivamente da pesquisa 104 estudantes, os quais responderam integralmente o questionário. Portanto, a amostra foi constituída por critérios de aleatoriedade e representatividade.

\section{Instrumento}

A coleta dos dados foi realizada por meio de um questionário online composto por questões que possibilitaram obter e analisar a percepção dos estudantes sobre o seu processo de apropriação de tecnologias sob as perspectivas pedagógica e tecnológica.

\section{Procedimento}

O questionário foi elaborado no Google Drive e o link disponibilizado no ambiente virtual de aprendizagem da disciplina DEAD. Os alunos foram convidados a responder o questionário ao final da oferta da disciplina, após terem realizado todas as atividades online. No início do questionário explicitamos os objetivos do estudo, as tarefas a realizar e a importância da participação em uma investigação deste âmbito. Também foram orientados a responder todas as questões propostas, de forma a refletir sobre suas percepções acerca das atividades desenvolvidas, tanto em relação ao aspecto pedagógico quanto ao aspecto tecnológico. Além desse objetivo, pretendíamos também obter um feedback que possibilitasse avaliarmos a disciplina quanto à forma de organização, aos conteúdos selecionados, à definição das metodologias e às tecnologias selecionadas, visando, a partir dos resultados, a ressignificação das diretrizes pedagógicas que embasaram o planejamento didático.

\section{Resultados}

Os resultados dessa investigação são apresentados a seguir, respeitando a sequência das questões que constituíram o questionário de pesquisa.

Quando questionados sobre o envolvimento pessoal nas atividades da disciplina DEAD, 57 estudantes consideraram seu envolvimento muito bom (acima de $80 \%$ ), seguido de 42 que consideraram bom (60 a 79\%). Somente 5 estudantes avaliaram como satisfatório (41 a $59 \%$ ). A porcentagem de cada categoria de resposta possível a essa questão encontra-se representada pela Figura 1.

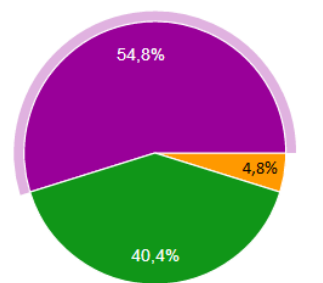

Insatisfatório (0\% a $10 \%)$ - Regular (11\% a $40 \%$ ) Satisfatório ( $41 \%$ a $59 \%$ ) Bom $(60 \%$ a $79 \%)$ Muito bom (acima de $80 \%$ )

Figura 1. Avaliação do desempenho pessoal na disciplina

As questões 2, 3, 4 e 5 solicitavam que os estudantes atribuíssem uma nota de 0 (zero) a 10 (dez) ao seu grau de dificuldade em relação à apropriação dos recursos digitais de rede utilizados para realizar as atividades da disciplina DEAD: Voki, Fábrica de Tirinhas ou Toondoo (o estudante poderia optar por um desses recursos ao realizar a atividade), Prezi e StoryJumper. Para essas 
questões o grau máximo de dificuldade deveria ser avaliado com a nota máxima 10 (dez) e 0 (zero) representaria a ausência de dificuldade. Portanto, formou-se uma escala decrescente em relação ao grau de dificuldade.

Com relação à apropriação do recurso tecnológico Voki 6 (seis) estudantes atribuíram nota zero, ou seja, afirmaram que não tiveram nenhuma dificuldade na apropriação desse recurso. Quanto ao grau máximo de dificuldade, 4 (quatro) estudantes atribuíram nota dez. Os estudantes que atribuíram nota acima de 6 (seis) somaram 49 (quarenta e nove), representando o quantitativo daqueles que tiveram mais dificuldade na apropriação do Voki. Os demais (55) atribuíram notas que variaram entre zero (0) e 5 (cinco), representando aqueles que tiveram menor grau de dificuldade ou nenhuma dificuldade com o recurso.

$\mathrm{Na}$ apropriação dos recursos tecnológicos Fábrica de Tirinhas ou Toondoo, 10 (dez) estudantes atribuíram nota zero e 4 atribuíram nota dez. Os estudantes que atribuíram nota acima de seis somaram 39 (trinta e nove), representando o quantitativo daqueles que tiveram mais dificuldade na apropriação desses recursos. Os demais (65) atribuíram notas que variaram entre 5 (cinco) e 0 (zero), representando aqueles que tiveram menor grau de dificuldade ou nenhuma dificuldade com o recurso.

Quanto à apropriação do recurso tecnológico Prezi, 8 (oito) estudantes atribuíram nota 0 (zero) e 3 (três) atribuíram nota dez. Os estudantes que atribuíram nota acima de seis somaram 40 (quarenta), representando o quantitativo daqueles que tiveram mais dificuldade na apropriação dos desses recursos. Os demais (64) atribuíram notas que variaram entre 5 (cinco) e 0 (zero), representando aqueles que tiveram menor grau de dificuldade ou nenhuma dificuldade com o recurso.

Por fim, com relação à apropriação do recurso tecnológico StoryJumper, 10 (dez) estudantes atribuíram nota 0 (zero) e 4 (quatro) estudantes atribuíram nota 10 (dez). Os estudantes que atribuíram nota acima de seis somaram 47 (quarenta e sete), representando o quantitativo daqueles que tiveram mais dificuldade na apropriação dos desses recursos. Os demais (57) atribuíram notas que variaram entre cinco e zero, representando aqueles que tiveram menor grau de dificuldade ou nenhuma dificuldade com o recurso.

A distribuição do número estudantes por nota de zero (0) a dez (10), expressando o grau de dificuldade na apropriação dos recursos digitais supracitados, está representada pela Tabela 1. Essa tabela está representada por nota que se refere à primeira linha e pelo número de estudantes respondentes (Est.) que corresponde à segunda linha.

\section{Tabela 1}

Grau de dificuldade dos estudantes na apropriação das tecnologias digitais

\begin{tabular}{|c|c|c|c|c|c|c|c|c|c|c|c|}
\hline \multicolumn{12}{|c|}{ Voki } \\
\hline Nota & 0 & 1 & 2 & 3 & 4 & 5 & 6 & 7 & 8 & 9 & 10 \\
\hline Est. & 6 & 10 & 14 & 7 & 2 & 16 & 8 & 11 & 15 & 11 & 4 \\
\hline \multicolumn{12}{|c|}{ Fábrica de Tirinhas/Toondoo } \\
\hline Nota & 0 & 1 & 2 & 3 & 4 & 5 & 6 & 7 & 8 & 9 & 10 \\
\hline Est. & 10 & 6 & 20 & 16 & 6 & 7 & 5 & 10 & 11 & 9 & 4 \\
\hline \multicolumn{12}{|c|}{ Prezi } \\
\hline Nota & 0 & 1 & 2 & 3 & 4 & 5 & 6 & 7 & 8 & 9 & 10 \\
\hline Est. & 8 & 8 & 14 & 14 & 7 & 13 & 3 & 15 & 12 & 7 & 3 \\
\hline \multicolumn{12}{|c|}{ StoryJumper } \\
\hline Nota & 0 & 1 & 2 & 3 & 4 & 5 & 6 & 7 & 8 & 9 & 10 \\
\hline Est. & 10 & 8 & 14 & 7 & 8 & 11 & 9 & 11 & 14 & 9 & 4 \\
\hline
\end{tabular}

De forma geral, o grau de dificuldade ou facilidade dos estudantes com relação à apropriação não variou significativamente em relação aos distintos recursos.

Quando questionados sobre como avaliam a contribuição dos recursos tecnológicos estudados para sua atuação na educação básica, nenhum dos estudantes se posicionou como indiferente. Nesse sentido, a Tabela 2 apresenta a distribuição da quantidade de alunos que se posicionaram nas categorias "contribuiu", "contribuiu parcialmente" e "não contribuiu". A Fábrica de Tirinhas, o Toondoo, o Prezi e o StoryJumper foram bem avaliados como recursos que contribuem para a atuação do professor na educação básica (Tabela 2). Dos 104 estudantes, somente 3 (três) não associaram a contribuição do Voki para a docência na educação básica e 2 (dois) estudantes entendem que o StoryJumper também não contribui para tal objetivo.

Tabela 2.

Avaliação da contribuição dos recursos para educação básica

\begin{tabular}{cccc}
\hline Recursos & Contribui & $\begin{array}{c}\text { Contribui } \\
\text { Parcialmente }\end{array}$ & $\begin{array}{c}\text { Não } \\
\text { contribui }\end{array}$ \\
\hline Voki & 74 & 27 & 3 \\
\hline $\begin{array}{c}\text { F. Tirinhas/ } \\
\text { Toondoo }\end{array}$ & 93 & 11 & 0 \\
\hline Prezi & 90 & 14 & 0 \\
\hline StoryJumper & 94 & 8 & 2 \\
\hline
\end{tabular}

Os dados da Tabela 2 demonstram que os estudantes percebem, em significativo número, que os recursos digitais utilizados durante a disciplina DEAD podem contribuir para a atuação docente na educação básica.

A pesquisa também evidenciou, com base na questão 7 do questionário - a realização das atividades da disciplina DEAD possibilitou que você ampliasse o seu conhecimento pedagógico sobre os recursos? -, que 99 estudantes $(95,2 \%)$ consideram que as atividades envolvendo o uso dos recursos digitais contribuíram para ampliar o conhecimento pedagógico sobre os mesmos.

Já na perspectiva qualitativa, destacamos os resultados obtidos a partir das demais questões do questionário. Quando solicitados a apontar as facilidades e dificuldades encontradas durante a realização das atividades da disciplina DEAD obtivemos respostas variadas, no entanto alguns elementos apareceram com maior frequência. Quanto às principais dificuldades mencionadas pelos estudantes, a que mais repercussão 
teve foi o fato de alguns sites estarem em língua inglesa, conforme podemos verificar nos excertos a seguir:

"Tive dificuldades em me apropriar do recurso tecnológico Voki e o Prezi, pois os programas eram em inglês e de difícil entendimento."

"Fácil acesso às atividades, ótimo esclarecimento na formulação das atividades. Uma das dificuldades foi o fato de alguns sites serem em inglês."

"Tinha algumas palavras em inglês e não português".

A segunda dificuldade mais recorrente nas respostas foi em relação ao tempo para cumprir as atividades:

"A dificuldade é no aprendizado, até nos apropriarmos do recurso utilizado. E o tempo eu acho curto, pois temos muitas atividades de várias disciplinas em um curto espaço de tempo."

"Falta de tempo para mais dedicação."

As facilidades apontadas pelos estudantes com relação a realização das atividades propostas incluíram a qualidade dos materiais didáticos selecionados, a importância dos conhecimentos para a docência na educação básica e as orientações didáticas das atividades de aprendizagem. Os excertos a seguir, representam esses posicionamentos dos estudantes:

"Como facilidade os materiais disponíveis."

"As facilidades são a respeito do nível de conhecimento adquirido que é muito satisfatório $e$ enriquecedor enquanto futuros docentes."

"Facilidade, porque os professores
disponibilizaram para nós alunos todas as orientações possíveis para a realização das atividades."

$\mathrm{Na}$ última questão solicitamos que os estudantes deixassem sugestões e críticas sobre as atividades propostas na disciplina DEAD. Dentre as críticas/sugestões, destacamos os comentários que reforçam a importância da apropriação das tecnologias para a atuação docente na educação básica, o interesse em ampliar os conhecimentos pedagógicos e tecnológicos sobre as TDR e a satisfação pelo contato com recursos desconhecidos. Seguem alguns exemplos de respostas que comprovam esses aspectos, respectivamente:

"Gostaria de aprender mais sobre a utilização destes materiais auxiliares nos próximos semestres, gostei de participar."

"Achei muito interessante todas as atividades, pois nos mostraram vários recursos tecnológicos, que fizeram que o meu conhecimento se ampliasse, recursos esses que não conhecia muito bem, mas que tive oportunidade de me apropriar, pensando a educação como processos de ensinar e aprender via o universo digital."

"Achei bem interessante os novos recursos digitais, recursos esses que poderão ser muito utilizados em sala de aula como incentivo a absorção do conhecimento de forma lúdica e descontraída."

Apesar de muitas respostas destacarem aspectos positivos sobre as atividades de aprendizagem que foram propostas, os estudantes também deixaram críticas que reforçaram aspectos que precisam ser analisados em um próximo planejamento da disciplina, os quais foram mencionados também nas questões anteriores, tais como: o prazo para realizar as atividades, o uso de sites em língua inglesa que não tenha a opção de tradução e a necessidade de orientações mais claras para realização das atividades de aprendizagem.

\section{Discussão}

De modo geral, os resultados apresentados nesse trabalho reforçam a importância e a necessidade de que o processo de apropriação de tecnologias digitais seja incorporado à formação de educadores e que extrapole o conhecimento sobre suas funcionalidades. É fundamental que os docentes saibam como utilizá-las mas, especialmente, saibam reconhecer o potencial pedagógico desses recursos para o alcance de objetivos de aprendizagem. Nesse sentido, acreditamos que gerar oportunidades de apropriação tecnológica durante a formação inicial contribui para que se possa avançar na inclusão das TDR em contextos escolares, especialmente na educação básica.

Os resultados desse estudo também sinalizam que estudantes de cursos superior a distância, apesar de utilizarem recursos digitais no seu proceso formativo, como os ambientes virtuais de aprendizagem, desconhecem e possuem dificuldades envolvendo o caráter tecnológico e pedagógico dos mesmos. Nesse sentido, entendemos que além de problematizar a leitura crítica da mídia e dos recursos tecnológicos disponíveis na web 2.0, é preciso pressupor processos formativos que provoquem o reconhecimento do potencial pedagógico dos recursos tecnológicos e que permitam o planejamento, a prática pedagógica e a avaliação envolvendo tecnologias educacionais (Marcon; Goedert, 2015).

Ao pensar no potencial pedagógico de uma tecnologia precisamos, inicialmente, romper com ideia que os recursos tecnológicos servem unicamente para "motivar", "inovar", "dinamizar" a prática do professor em sala de aula. Inicialmente é preciso apropriar-se da tecnologia: utilizar, testar, conhecer as funcionalidades, as limitações, os recursos disponíveis, os aspectos técnicos, as linguagens, enfim, conhecer o recurso que está sendo trabalhado.

Ao entender de forma aprofundada as funcionalidades do recurso, precisamos ter clareza sobre a adequação da ferramenta à etapa da educação básica que estamos trabalhando. O recurso digital selecionado é adequado ao grupo que estou atuando? Além disso, é preciso considerar a intencionalidade pedagógica: quais são os objetivos de ensino e quais são os objetivos de aprendizagem? Que conteúdos serão estudados? Que conceitos estarão sendo trabalhados? Como a atividade será avaliada?

Esses são alguns dos questionamentos que levamos à discussão para os acadêmicos da disciplina Didática da Educação a Distância.

\section{Referências}

Coutinho, C. P. (2009). Tecnologias Web 2.0 na sala de aula: três propostas de futuros profesores de Português. Educação, formação \& tecnologías, v. 2, n. 1. 2Título 
Revista. $N^{o}$ Vol, primerapágartículo-úlimapágartículo. http://www.eft.educom.pt/index.php/eft/issue/view/7 . Marcon, K. (2015). A inclusão digital de educadores a distância: Estudo multicaso nas Universidades Abertas do Brasil e de Portugal. 2015. Tese (Doutorado em Educação). Programa de Pós-Graduação em Educação, Universidade Federal do Rio Grande do Sul.

Marcon, K. \& Goedert, L. (2015). Apropriação tecnológica na formação inicial de professores: uma experiência no curso de Pedagogia CEAD/UDESC. In: Pandini, C. et al. (Orgs.). Práticas pedagógicas na educação a distância: reflexões, experiências $e$ processos. Florianópolis: UDESC.

Moreira, J. A., Monteiro, A. \& Barros, D. M. (2015). Formação de professores para a Web 2.0: o TPACK como referencial teórico. In: Moreira, J. A.; Barros, D. M.; Monteiro, A. Inovação e formação na sociedade digital: ambientes virtuais, tecnologias e serious games. 1. ed. Porto: Whitebooks.

Riedner, D. D. T. \& Pischetola, M. (2016). Tecnologias Digitais no Ensino Superior: uma possibilidade de inovação das práticas? Educação, Formação \& Tecnologias, v. 9, n. 2, pp. 37-55. 